This is an author produced version of a paper published in Immunology Letters. This paper has been peer-reviewed but does not include the final publisher proofcorrections or journal pagination.

Citation for the published paper:

Holmdahl, Rikard

"Dissection of the genetic complexity of arthritis using animal models."

Immunol Lett. 2006 Mar 15;103(2):86-91.

http://dx.doi.org/10.1016/j.imlet.2005.10.025

Access to the published version may require journal subscription.

Published with permission from: Elsevier 


\section{Dissection of the genetic complexity of arthritis using animal models}

Rikard Holmdahl

Medical Inflammation Research, BMC I11, Lund University, S-22184 Lund, Sweden

Rikard.Holmdahl@med.lu.se

Keywords; arthritis, oxidative burst, genetics, animal models, MHC class II 


\begin{abstract}
Rheumatoid arthritis [RA] is a chronic inflammatory disease directed towards peripheral joints. As all common diseases it is associated with several genes and a multitude of environmental factors. In addition, in similarity with most other complex diseases, it is defined only on the basis of clinical signs and symtoms, it is therefore more properly classified as a syndrome rather than a distinct disease entity.

This complexity of RA has led to difficulties in finding the underlying genes. In spite of large efforts it is still only the MHC class II region that reaches genome wide significance in confirmed studies. However, this has been known for decades and we are still unable to conclusively identify the underlying gene/s. We hypothesize that a MHC class II gene is involved and although we have detailed knowledge on both structure and function we do not know its possible pathogenic role in RA.

In this review I will argue for the usefulness of animal models as a tool to identify genes and pathways associated with disease. The examples to be discussed genes controlling the oxidative burst pathways and MHC class II genes.
\end{abstract}




\section{From disease to genes}

An ideal model for human RA should mimic the complexity of the human disease in being polygenic and dependent on environmental factors. The advantage of animals is that both genetics and environment can be better controlled and in addition hypothesis can be experimentally tested. RA is a syndrome, likely composed of several distinct disease entities, and so are the animal models. The heterogeneity is reflected in the large number of different models with clearly different pathogenesis. It is likely that each of them reflect distinct subsets of RA and provide unique possibilities to study pathogenic pathways in controlled settings. Studies of the animal models need to be performed with the same approach as we investigate human disease, starting with the disease to unravel the genetic basis. This provides the proper contextual setting which is critical for understanding the molecular pathogenesis. Along this approach the animal models are now genetically dissected to determine the genetic polymorphism that allow the pathogenic development of chronic arthritis. This is a difficult approach, although not as difficult as in humans, but recently progress have been made showing that this will be possible.

The approach clearly demands diseases in animals that as close as it is possible mimics the corresponding human disease. The most obvious difference is often not the species difference but differences in how the experimental animal models are studies as compared with humans. The vast majority of all so far published data use the animal models for studies of only the acute phase of the disease whereas in humans basically no studies are devoted to this phase as RA patients most likely are diagnosed several years after their disease onset and clearly at least a half year after their clinical onset. There are evidence that acute and chronic phases are controlled by different sets of genes and definitely they differ in their pathogenic 
mechanisms. Another main difference is that we do not yet know the environmental factors triggering RA and for using animal models we need a high and reproducible frequency. Therefore, we use environmental factors that give arthritis in animals but for which knowledge is lacking in humans. Nevertheless, many adjuvant or self antigens used in experimental arthritis are likely to be involved in different phases also in the human disease. Gradually, we have learned to develop better and more useful animal models and some of them will be discussed.

\section{The pristane induced arthritis in rats}

A still unexplained phenomena is that severe arthritis develpops in many rats after injection of various adjuvant. This was originally induced using complete Freund's adjuvant, i.e. mycobacteria cells walls suspended in mineral oil [1]. Many years later it was noted that the mineral oils that supported the induction of arthritis were in fact arthritogenic by themselves [2]. It was also found that subcutaneous administration of adjuvant compounds, such as pristane and squalen, which bear no relation to bacterias and which are present in our bodies, were highly effective in inducing arthritis $[3,4]$. The common action of these non-bacterial arthritogenic adjuvants is that they do stimulate innate immunity but not adaptive immunity as they are not immunogenic by themselves. There are however so far no evidence that they operate through known receptors like TLRs and NOD2, but more likely through so far unknown innate immune mechanisms. Surprisingly, these non-bacterial and nonimmunogenic adjuvants produce inflammation confined to the joints and offer better experimental models for RA than the earlier commonly used "adjuvant arthritis" i.e. mycobacterium in oil induced arthritis [MIA] model. Less than two weeks after a 
subcutaneous injection of pristane, arthritis in the peripheral joints suddenly develops. In certain rat strains like the DA, the arthritis proceeds as a chronic relapsing disease. Surprisingly, no consistent immune response to any specific cartilage component has yet been observed although rheumatoid factors are present in serum [5]. A role for cartilage proteins in regulating disease activity is possible as the disease can be prevented and in fact therapeutically ameliorated by nasal vaccination with various cartilage proteins [6]. Both the initiation and the chronic progression of the arthritis is $\mathrm{T}$ cell dependent as shown by in vivo administration of antibodies to ab $\mathrm{T}$ cells $[3,4,7]$ and through transfer of the disease with CD4+ $\mathrm{T}$ cells expressing ab $\mathrm{T}$ cell receptor [8]. Interestingly the arthritogenic $\mathrm{T}$ cells are MHC class II restricted and recognize both DQ and DR class II alleles [8]. Together with the observation that the chronic disease course is associated with the MHC region $[3,4,7]$, this suggest that $\mathrm{T}$ cells activated after pristane injection recognize a self peptide MHC class II complex. The involvement of different MHC class II molecules and TCR V genes argues for a role of many different self antigens, although none has so far been identified.

A disease to gene approach has been used to identify the pathogenic pathways in this disease. The difficulties in using genetic manipulations in the rat have simplified this approach in that work has not been misled to the same extent as in the mouse by suggestions that stems from such approaches. Thus so far, linkage analysis of genetically segregating crosses has shown that the disease is polygenic and a large part of the variance could be explained by more than 20 quantitative trait loci [QTL] [9-15]. Interestingly, they seem to control distinct phases of the disease such as arthritis onset, clinical severity, joint erosion and chronicity.

Positional cloning of the underlying genes has however been proven to be a difficult task. Still, however, with much more powerful possibilities that are at hand in humans. With 
inbred rodents it is possible to make congenic strains, in which quantitative trait locus containing one or several disease genes are isolated. By selecting recombinant congenic fragments and testing the strains for disease the fragment can gradually be reduced. This approach has so far been the only successful approach to conclusively identify the underlying genes. Thus, such an approach was used to clone Ncf1 from the Pia4 locus identified in crosses between DA and E3 strains [16]. The Ncf1 gene, also known as p47phox, codes for a protein in the NADPH oxidase complex, that mediates oxidative burst. Surprisingly a lower oxidative burst capacity was associated with more severe arthritis. The effect was found to operate before $\mathrm{T}$ cell activation and therefore also controls the degree of autoimmunity, linking innate and adaptive immunity and giving a new perspective on the development of arthritis. The nucleotide variance controlling the degree of oxidative burst has been identified but the molecular mechanism of this effect has not been resolved. Interestingly a high degree of polymorphism among different inbred rat strains as well as in wild rats have been found and there is also a considerable polymorphism in both the $N c f 1$ gene and in genes associated with the pathway in other species. This, did in fact open the possibility to study the effect of other mutations in the $N c f 1$ gene for development of the more classical arthritis model in the mouse, the collagen induced arthritis (CIA).

\section{Collagen II induced arthritis (CIA)}

Immunization with the major collagen in cartilage, type II collagen (CII), leads to an autoimmune response and as a consequence, sudden onset of severe arthritis. Although it is usually necessary to emulsify the CII in adjuvant, such as mineral oil or the complete Freund's adjuvant, the disease can be distinguished from the various forms of adjuvant 
arthritis [17]. Both susceptibility and the chronicity of the disease course are genetically controlled. In the most commonly used mouse strain, DBA/1, the arthritis is severe and acute whereas in other strains like those with a $\mathrm{C} 57 \mathrm{Bl} / 10$ background such as the B10.Q or B10.RIII strains, the arthritis is milder but eventually later develop into a more chronic relapsing disease course [18-20]. The disease is critically dependent on both a T-and a B-cell response to CII and pathogenic antibodies play a role in the inflammatory attack on the joints [21]. The collagen antibody induced arthritis (CAIA) is inducible with certain CII specific monoclonal antibodies [22]. These CII-specific antibodies bind to the cartilage surface, fix complement, attract neutrophilic granulocytes and activate macrophages in a process independent of the immune system [23].

CIA is a complex, polygenic disease, in similarity with the PIA model. In the CIA model, however, the autoimmune process is already determined by the induction through immunization with a defined antigen. Not surprisingly, the major histocompatibility complex $[\mathrm{MHC}]$ class II polymorphism is important for determining susceptibility but there is also a major influence by a large number of other unknown genes. The major gene regions have been identified through genetic segregation experiments in both mice and rats, which have given an overall picture of the genetic inheritance of the susceptibility [24-26]. As in other complex diseases, these genes operate in concert and can only be identified through isolation in a proper genetic and environmental context i.e. as congenic strains used under specified conditions $[27,28]$. One of the most important loci is the $M H C$ region and the identification of arthritis-associated genes within this region has provided an example that a "disease to gene” approach is essential and instructive. 


\section{The role of the major histocompatibility complex}

The establishment of inbred congenic strains did not only allow the identification of the major histocompatibility region a half century ago but also provided congenic strains useful for studies of disease associations. Such studies showed that CIA is most strongly associated with the $H 2^{q}$ and $H 2^{r}$ haplotypes whereas most other haplotypes such as b, s, d and p are relatively resistant [29]. The major underlying gene explaining the association with the $H 2^{q}$ haplotype has been identified as the $A^{q}$ beta gene and the disease causing polymorphic nucleotides are also known [30]. Moreover, the immunodominant peptide derived from the CII molecule bound to the arthritis-associated q variant of the $A\left(A^{q}\right)$ molecule has been found to be located between positions 260 and 270 of CII [31]. This is a glycopeptide with an oligosaccharide pointing towards the $\mathrm{T}$ cell receptor and is recognised by most of the CIIreactive $T$ cells [32]. Interestingly, the peptide-binding pocket of the $\mathrm{A}^{\mathrm{q}}$ molecule is very similar to that of the DR4 [DRB1*0401/DRA] and DR1 molecules, i.e. the shared epitope, which are associated with RA. Furthermore, mice transgenically expressing $D R 4$ or $D R 1$ are susceptible to CIA and respond to a peptide from the same CII region [33-35] and CII reactive $\mathrm{T}$ cells from RA patients seem to predominantly recognize the glycopeptide [36]. These findings suggest a model for studies of RA that not only mimic some basic pathogenic events but maybe also share some critical structural similarities. Most importantly, it allows further studies of the pathogenic role of MHC class II polymorphism.

\section{Autoimmune recognition of cartilage}

It is important to emphasise that the identified structural interaction between MHC class II+peptide complexes and T cells does not give us the answer to the pathogenesis of CIA 
[or RA], but rather a better tool for further analysis. An important question is how the immune system in fact interacts with the peripheral joints, i.e. how autoreactive $\mathrm{T}$ and $\mathrm{B}$ cells are normally tolerized and what happens in the pathologic situation, after their activation by CII immunisation. Most of the T cells reactive with the rat CII256-270 peptide do not cross-react with the corresponding peptide from mouse CII. The difference between the heterologous and the homologous peptide is position 266 in which the rat has a glutamic acid (E) and the mouse an aspartic acid (D), which leads to a weaker binding of the mouse peptide to $\mathrm{A}^{\mathrm{q}}$. The importance of this minor difference was demonstrated in transgenic mice expressing CII mutated to express a glutamic acid at this position [37]. When mutated CII was expressed in cartilage the T cell response to CII was partially but not completely tolerized. The mice were susceptible to arthritis but the incidence was low, similar to what is seen in mice immunised with homologous CII. This finding shows that a normal interaction between cartilage and $\mathrm{T}$ cells leads to the activation of $\mathrm{T}$ cells with less capacity to induce arthritis or alternatively with regulatory properties. Clearly, the $\mathrm{T}$ cells have recognized the antigens in a physiologic setting but survived this event. These remaining $\mathrm{T}$ cells are likely to have a function for instance to actively regulate arthritis development. In fact such regulatory $\mathrm{T}$ cells have been identified but is not of the classical $\mathrm{CD} 4^{+} \mathrm{CD} 25^{+}$type but are $\mathrm{CD} 4^{+} \mathrm{CD} 152^{+}$[38]. However, the partially tolerized $\mathrm{T}$ cells may also under extreme circumstances [such as CII immunisation] mediate arthritis. In contrast, B cells reactive with CII are not tolerized and as soon as the T cells are activated, even in a partially tolerized state, they help B cells to produce autoreactive and pathogenic antibodies. It is possible that a similar situation may exist in humans that could explain the difficulties in isolating CII reactive T cells compared with the relative 
ease in which CII-reactive B cells can be detected in the joints. Interestingly, the susceptibility to arthritis and to CII autoimmunity by the E264D CII mutation is genetically controlled. If on the $\mathrm{C} 57 \mathrm{Bl} / 10$ background, the mice are completely resistant to arthritis and autoreactive T cells to CII are only barely detectable [39]. Thus, tolerance is genetically controlled also by other genes than MHC class II.

\section{Identification of Ncf1 in the mouse}

The polygenic control of CIA is as complex as in PIA. At least 25 loci are of importance in crosses that involve the C57/Black10 gene background with a number of other mouse backgrounds, but which share the $M H C[H 2 q]$ gene region [25, 26, 40, 41]. The pattern and penetrance of such loci between the different crosses varies, indicating the complexity of different pathways in CIA. An interesting candidate gene is certainly $N c f 1$, as this was already identified in rats. However, a corresponding polymorphism of Ncf1 as found in the rat is not present in the mouse. Instead, polymorphism occurs in several genes in the $N c f 1$ associated pathway and some of these are within the identified loci associated with CIA. Nevertheless, it would have been of value to investigate mutations in the Ncf1 gene as this would confirm a link between the oxidative burst pathway and arthritis and would also allow more precise analysis of the function of Ncf1 in T cell autoimmunity. In fact, such a mutation was reported to occur in a leptin receptor-deficient C57Bl/6 mouse [42]. This mutation is different from the one identified in the rat and was located in a splicing site. It dramatically reduced expression of a functional Ncf1 and led to an impaired oxidative burst. The Ncf1 mutation was backcrossed to the CIA susceptible B10.Q mouse, a C57Bl/10 MHC congenic mouse strain, which also express that arthritis permissive Aq MHC class II gene [20]. 
Importantly, this mouse developed a severe chronic relapsing arthritis after immunization with CII. It also developed an enhanced delayed type hypersensitivity reaction to CII, an in vivo test known to be $\mathrm{T}$ cell dependent. In accordance with an enhanced CII $\mathrm{T}$ cell autoreactivity, the Ncf1 mutated mouse developed high levels of IgG antibodies to CII. Thus, as earlier shown in the rat, the Ncf1 variant that allow a lower oxidative burst is associated with the activation of autoreactive $\mathrm{T}$ cells and the development of severe arthritis. Interestingly, this mouse also develops arthritis spontaneously at the postpartum period, known to be a vulnerable period for development of CIA [43]. The spontaneous arthritis was as severe as CIA and developed into a chronic relapsing disease course. The arthritic mice also had a weak but significant antibody response to CII, in fact specific for epitopes that are targeted by arthritogenic antibodies. The development of inflammation in the joints, but not in other tissues, is difficult to explain as there is no obvious link to the specificity of an immune response. It is clearly important to investigate the role of Ncf1 not only in arthritis but also in other inflammatory conditions. So far, experiments using models for multiple sclerosis shown that this may be complicated as induction of disease with a MOG [myelin oligodendrocytic glycoprotein] derived peptide was less efficient in the Ncf1 mutated mouse whereas the induction of EAE with the native MOG protein led to an enhancement, similar to the findings in arthritis.

In humans, complete Ncf1 deficiency cause chronic granulomatous disease (CGD)[44]. CGD is characterized by an increased infectious susceptibility but also a chronic granulomatous inflammation in the intestinal tract. There is an overrepresentation of autoimmune disease but the numbers of CGD patients is too low to conclude about specific association to certain autoimmune diseases. A mouse made deficient for Ncf1 through gene targeting has been 
reported to develop a CGD like disease [45], but show a complicated pattern of susceptibility to both infectious [46, 47] and inflammatory models [48-53]. The Ncf1 deficient mouse was shown to be very resistant to development of experimental autoimmune encephalomyelitis (EAE) [53] but developed an enhanced severity of arthritis triggered with zymosan [50]. In contrast, the B10.Q Ncf1 mutated mouse has so far no apparent signs of CGD and show an enhancing effect of EAE when induced with recombinant MOG protein. There are many possible explanations for these discrepancies as the Ncf1 mutated mouse also has a large number of linked 129 derived genes and has a complete deficiency of Ncf1 whereas the B10.Q Ncf1 mouse is only one nucleotide difference, which does not completely delete the gene. This may have bearings for the human disease as incomplete penetrance and polymorphism of Ncf1 may be of equal importance but is not associated with CGD.

\section{Conclusions}

It is apparent that a "disease to gene" approach has revealed previously unknown pathways of importance for both the control of autoreactive $\mathrm{T}$ cells as well as for the development of arthritis. Maybe more important, this pathways are likely to be relevant as they are controlled by a genetic polymorphism that is naturally occurring and therefore likely to be selected by "real" manipulations like the environment both rodents and humans are living in. It is important to emphasize that such a selection is operating on the pathway and not on specific genetic polymorphism or single genes. This was indicated in the comparative analysis of the Ncf1 gene and its pathways of mice and rats although this analysis is only in its beginning. Likewise we do not yet know the importance of the polymorphism of the $N c f 1$ gene or its related pathway in humans. However, it is known that the $N c f 1$ gene is in an unstable region 
with very recent duplications with several pseudo-, truncated and normal with a high degree of polymorphism. The importance of this pathway in humans remains to be investigated and as a prerequisite for these investigations we need to unravel the secrets in experimental animals in which experiments can be conclusively designed.

\section{References}

1. Whitehouse MW, Orr KJ, Beck FWJ, Pearson CM. Freund's adjuvants:

Relationsip to arthritogenicity and adjuvanticity in rats to vehicle composition. Immunology 1974;27:311-330.

2. Holmdahl R, Goldschmidt TJ, Kleinau S, Kvick C, Jonsson R. Arthritis induced in rats with adjuvant oil is a genetically restricted, alpha beta T-cell dependent autoimmune disease. Immunology 1992;76:197-202.

3. Vingsbo C, Sahlstrand P, Brun JG, Jonsson R, Saxne T, Holmdahl R. Pristaneinduced arthritis in rats: a new model for rheumatoid arthritis with a chronic disease course influenced by both major histocompatibility complex and nonmajor histocompatibility complex genes. Am J Pathol 1996;149:1675-1683.

4. Carlson BC, Jansson AM, Larsson A, Bucht A, Lorentzen JC. The endogenous adjuvant squalene can induce a chronic T-cell-mediated arthritis in rats. Am J Pathol 2000;156:2057-2065.

5. Wernhoff P, Olofsson P, Holmdahl R. The genetic control of rheumatoid factor production in a rat model for rheumatoid arthritis. Arthritis Rheum 2003;48:35843596.

6. Lu S, Holmdahl R. Different therapeutic and bystander effects by intranasal administration of homologous type II and type IX collagens on the collageninduced arthritis and pristane-induced arthritis in rats. Clin Immunol 1999;90:119127.

7. Vingsbo C, Jonsson R, Holmdahl R. Avridine-induced arthritis in rats; a T celldependent chronic disease influenced both by MHC genes and by non-MHC genes. Clin Exp Immunol 1995;99:359-363.

8. Holmberg J, Yamada H, Olofsson P, Lu S, Holmdahl R. Pristane activate MHC class II-restricted T cells, which transfer arthritis. J Immunol 2005; acc for publication.

9. Vingsbo-Lundberg C, Nordquist N, Olofsson P, Sundvall M, Saxne T, Pettersson $\mathrm{U}$, et al. Genetic control of arthritis onset, severity and chronicity in a model for rheumatoid arthritis in rats. Nat Genet 1998;20:401-404.

10. Lorentzen JC, Glaser A, Jacobsson L, Galli J, Fakhrai-Rad H, Klareskog L, et al. Identification of rat susceptibility loci for adjuvant-oil induced arthritis. Proc Natl Acad Sci U S A 1998;95:6383-6387. 
11. Olofsson P, Holmberg J, Pettersson U, Holmdahl R. Identification and isolation of dominant susceptibility loci for pristane induced arthritis. J Immunol 2003;171:407-416.

12. Olofsson P, Lu S, Holmberg J, Song T, Wernhoff P, Pettersson U, et al. A comparative genetic analysis between collagen-induced arthritis and pristaneinduced arthritis. Arthritis Rheum 2003;48:2332-42.

13. Nordquist N, Olofsson P, Vingsbo-Lundberg C, Pettersson U, Holmdahl R. Complex genetic control in a rat model for rheumatoid arthritis. J Autoimmunity 2000;15:425-432.

14. Kawahito Y, Cannon GW, Gulko PS, Remmers EF, Longman RE, Reese VR, et al. Localization of quantitative trait loci regulating adjuvant-induced arthritis in rats: evidence for genetic factors common to multiple autoimmune diseases. J Immunol 1998;161:4411-4419.

15. Joe B, Cannon GW, Griffiths MM, Dobbins DE, Gulko PS, Wilder RL, et al. Evaluation of quantitative trait loci regulating severity of mycobacterial adjuvantinduced arthritis in monocongenic and polycongenic rats: Identification of a new regulatory locus on rat chromosome 10 and evidence of overlap with rheumatoid arthritis susceptibility loci. Arthritis Rheum 2002;46:1075-1085.

16. Olofsson P, Holmberg J, Tordsson J, Lu S, Åkerström B, Holmdahl R. Positional identification of Ncf1 as a gene that regulates arthritis severity in rats. Nat Genet 2003;33:25-32.

17. Holmdahl R, Kvick C. Vaccination and genetic experiments demonstrate that adjuvant oil induced arthritis and homologous type II collagen induced arthritis in the same rat strain are different diseases. Clin Exp Immunol 1992;88:96-100.

18. Holmdahl R, Andersson M, Goldschmidt TJ, Gustafsson K, Jansson L, Mo JA. Type II collagen autoimmunity in animals and provocations leading to arthritis. Immunol Rev 1990;118:193-232.

19. Svensson L, Nandakumar KS, Johansson A, Jansson L, Holmdahl R. IL-4deficient mice develop less acute but more chronic relapsing collagen-induced arthritis. Eur J Immunol 2002;32:2944-2953.

20. Hultqvist M, Olofsson P, Holmberg J, Bäckström BT, Tordsson J, Holmdahl R. Enhanced autoimmunity, arthritis, and encephalomyelitis in mice with a reduced oxidative burst due to a mutation in the Ncf1 gene. Proc Natl Acad Sci U S A 2004;101:12646-51.

21. Stuart JM, Dixon FJ. Serum transfer of collagen induced arthritis in mice. J Exp Med 1983;158:378-392.

22. Holmdahl R, Rubin K, Klareskog L, Larsson E, Wigzell H. Characterization of the antibody response in mice with type II collagen-induced arthritis, using monoclonal anti-type II collagen antibodies. Arthritis Rheum 1986;29:400-410.

23. Nandakumar KS, Svensson L, Holmdahl R. Collagen type II specific monoclonal antibody induced arthritis [CAIA] in mice. Description of the disease and the influence of age, sex, and genes. Am J Pathol 2003;163:1827-37.

24. Remmers EF, Longman RE, Du Y, O'Hare A, Cannon GW, Griffiths MM, et al. A genome scan localizes five non-MHC loci controlling collagen-induced arthritis in rats. Nature Genet 1996;14:82-85. 
25. Jirholt J, Cook A, Emahazion T, Sundvall M, Jansson L, Nordquist N, et al. Genetic linkage analysis of collagen-induced arthritis in the mouse. Eur J Immunol 1998;28:3321-3328.

26. Yang HT, Jirholt J, Svensson L, Sundvall M, Jansson L, Pettersson U, et al. Identification of genes controlling collagen-induced arthritis in mice: striking homology with susceptibility loci previously identified in the rat. J Immunol 1999;163:2916-2921.

27. Johannesson M, Karlsson J, Wernhoff P, Nandakumar KS, Lindqvist AK, Olsson $\mathrm{L}$, et al. Identification of epistasis through a partial advanced intercross reveals three arthritis loci within the Cia5 QTL in mice. Genes Immun 2005;6:175-85.

28. Karlsson J, Johannesson M, Lindvall T, Wernhoff P, Holmdahl R, Andersson A. Genetic Interactions in Eae2 Control Collagen-Induced Arthritis and the CD4+/CD8+ T Cell Ratio. J Immunol 2005;174:533-41.

29. Wooley PH, Luthra HS, Stuart JM, David CS. Type II collagen induced arthritis in mice. I. Major histocompatibility complex [I-region] linkage and antibody correlates. J Exp Med 1981;154:688-700.

30. Brunsberg U, Gustafsson K, Jansson L, Michaëlsson E, Ährlund-Richter L, Pettersson S, et al. Expression of a transgenic class II Ab gene confers susceptibility to collagen-induced arthritis. Eur J Immunol 1994;24:1698-1702.

31. Michaëlsson E, Andersson M, Engström A, Holmdahl R. Identification of an immunodominant type-II collagen peptide recognized by T cells in $\mathrm{H}-2 \mathrm{q}$ mice: self tolerance at the level of determinant selection. Eur J Immunol 1992;22:181925.

32. Michaëlsson E, Malmström V, Reis S, Burkhardt H, Engström Å, Holmdahl R. T cell recognition of carbohydrates on type II collagen. J Exp Med 1994;30:745749.

33. Rosloniec EF, Brand DD, Myers LK, Whittington KB, Gumanovskaya M, Zaller DM, et al. An HLA-DR1 transgene confers susceptibility to collagen-induced arthritis elicited with human type II collagen. J Exp Med 1997;185:1113-1122.

34. Rosloniec EF, Brand DD, Myers LK, Esaki Y, Whittington KB, Zaller DM, et al. Induction of autoimmune arthritis in HLA-DR4 [DRB1*0401] transgenic mice by immunization with human and bovine type II collagen. J Immunol 1998;160:2573-8.

35. Andersson EC, Hansen BE, Jacobsen H, Madsen LS, Andersen CB, Engberg J, et al. Definition of MHC and T cell receptor contacts in the HLA-DR4 restricted immunodominant epitope in type II collagen and characterization of collageninduced arthritis in HLA-DR4 and human CD4 transgenic mice. Proc Natl Acad Sci U S A 1998;95:7574-7569.

36. Bäcklund J, Carlsen S, Höger T, Holm B, Fugger L, Kihlberg J, et al. Predominant selection of T cells specific for glycosylated collagen type II peptide [263-270] in humanized transgenic mice and in rheumatoid arthritis. Proc Natl Acad Sci U S A 2002;99:9960-9965.

37. Malmström V, Michaëlsson E, Burkhardt H, Mattsson R, Vuorio E, Holmdahl R. Systemic versus cartilage-specific expression of a type II collagen-specific T-cell epitope determines the level of tolerance and susceptibility to arthritis. Proc Natl Acad Sci [USA] 1996;93:4480-4485. 
38. Treschow AP, Backlund J, Holmdahl R, Issazadeh-Navikas S. Intrinsic tolerance in autologous collagen-induced arthritis is generated by CD152-dependent CD4+ suppressor cells. J Immunol 2005;174:6742-50.

39. Bäcklund J, Nandakumar KS, Bockermann R, Mori L, Holmdahl R. Genetic control of tolerance to type II collagen and development of arthritis in an autologous collagen-induced arthritis model. J Immunol 2003;171:3493-9.

40. Johansson ÅCM, Sundler M, Kjellén P, Johannesson M, Cook A, Lindqvist AK, et al. Genetic control of collagen-induced arthritis in a cross with NOD and C57BL/10 mice is dependent on gene regions encoding complement factor 5 and FcgammaRIIb and is not associated with loci controlling diabetes. Eur J Immunol 2001;31:1847-1856.

41. Bauer K, Yu X, Wernhoff P, Koczan D, Thiesen HJ, Ibrahim SM. Identification of new quantitative trait loci in mice with collagen-induced arthritis. Arthritis Rheum 2004;50:3721-8.

42. Huang CK, Zhan L, Hannigan MO, Ai Y, Leto TL. P47[phox]-deficient NADPH oxidase defect in neutrophils of diabetic mouse strains, C57BL/6J-m db/db and db/+. J Leukoc Biol 2000;67:210-215.

43. Mattsson R, Mattsson A, Holmdahl R, Whyte A, Rook GAW. Maintained pregnancy levels of oestrogen afford complete protection from post-partum exacerbation of collagen-induced arthritis. Clin Exp Immunol 1991;85:41-47.

44. Segal BH, Leto TL, Gallin JI, Malech HL, Holland SM. Genetic, biochemical, and clinical features of chronic granulomatous disease. Medicine [Baltimore] 2000;79:170-200.

45. Jackson SH, Gallin JI, Holland SM. The p47phox mouse knock-out model of chronic granulomatous disease. J Exp Med 1995;182:751-8.

46. Crandall H, Ma Y, Dunn DM, Sundsbak RS, Zachary JF, Olofsson P, et al. Bb2Bb3 Regulation of Murine Lyme Arthritis Is Distinct from Ncf1 and Independent of the Phagocyte Nicotinamide Adenine Dinucleotide Phosphate Oxidase. Am J Pathol 2005;167:775-85.

47. Cooper AM, Segal BH, Frank AA, Holland SM, Orme IM. Transient loss of resistance to pulmonary tuberculosis in $\mathrm{p} 47[\mathrm{phox}-/-$ ] mice. Infect Immun 2000;68:1231-1234.

48. Segal BH, Doherty TM, Wynn TA, Cheever AW, Sher A, Holland SM. The p47[phox-/-] mouse model of chronic granulomatous disease has normal granuloma formation and cytokine responses to Mycobacterium avium and Schistosoma mansoni eggs. Infect Immun 1999;67:1659-1665.

49. Segal BH, Kuhns DB, Ding L, Gallin JI, Holland SM. Thioglycollate peritonitis in mice lacking C5, 5-lipoxygenase, or p47[phox]: complement, leukotrienes, and reactive oxidants in acute inflammation. J Leukoc Biol 2002;71:410-6.

50. van de Loo FA, Bennink MB, Arntz OJ, Smeets RL, Lubberts E, Joosten LA, et al. Deficiency of NADPH oxidase components p47phox and gp91phox caused granulomatous synovitis and increased connective tissue destruction in experimental arthritis models. Am J Pathol 2003;163:1525-37.

51. Gao XP, Standiford TJ, Rahman A, Newstead M, Holland SM, Dinauer MC, et al. Role of NADPH oxidase in the mechanism of lung neutrophil sequestration and 
microvessel injury induced by Gram-negative sepsis: studies in p47phox-/- and gp91phox-/- mice. J Immunol 2002;168:3974-82.

52. Barry-Lane PA, Patterson C, van der Merwe M, Hu Z, Holland SM, Yeh ET, et al. p47phox is required for atherosclerotic lesion progression in ApoE[-/-] mice. $\mathrm{J}$ Clin Invest 2001;108:1513-22.

53. van der Veen RC, Dietlin TA, Hofman FM, Pen L, Segal BH, Holland SM. Superoxide prevents nitric oxide-mediated suppression of helper T lymphocytes: decreased autoimmune encephalomyelitis in nicotinamide adenine dinucleotide phosphate oxidase knockout mice. J Immunol 2000;164:5177-51783. 